Motrivivência Ano XXII, No 34, P. 245-255 Jun./2010

DOI:10.5007/2175-8042.2010n34p245

\title{
OS “LEGADOS" DOS MEGAEVENTOS ESPORTIVOS NO BRASIL: algumas notas e reflexões
}

\author{
Juliano de Souza? \\ Wanderley Marchi Júnior ${ }^{2}$
}

\begin{abstract}
Resumo Abstract
No presente texto procuramos esboçar algumas reflexões críticas

sobre a temática do "legado" esportivo e sobre a forma com que

esta idéia vem sendo lançada e tem repercutido no espaço social brasileiro. Mais precisamente, nos

propomos em avaliar, de forma preliminar e sem cair na tentação do profetismo, algumas das dimensões

sociais (traduzidas sob o termo

"legados") inerentes à conjuntura de realização desses megaeventos esportivos no Brasil.

Palavras-chave: "Legado", Megaeventos, Brasil.

In this paper we seek to outline some critical reflections on the theme of "legacy" on sports and the way that this idea has been launched and is reflected in the Brazilian social space. More precisely, we propose to evaluate, on a preliminary basis and without the temptation of prophecy, some of the social dimensions (translated under the term "legacy") inherent in the context of achieving these sporting mega events in Brazil.

Keywords: "Legacy", Mega Events, Brazil,

1 Mestrando em Educação Física. Centro de Pesquisas em Esporte, Lazer e Sociedade (CEPELS). Asociación Latinoamerica de Estudios Socioculturales del Deporte (ALESDE). Universidade Federal do Paraná. Contato: julianoedf@yahoo.com.br.

2 Doutor em Educação Física. Centro de Pesquisas em Esporte, Lazer e Sociedade (CEPELS). Asociación Latinoamerica de Estudios Socioculturales del Deporte (ALESDE). Universidade Federal do Paraná. Contato: marchijr@ufpr.br.
\end{abstract}


As breves reflexões e discussões sobre os "legados" esportivos que propomos nesse texto, partem de algumas inquietações que nos tem sido suscitadas nesses últimos anos por conta de nossa participação em alguns eventos da Sociologia e da Educação Física, especialmente, nos grupos de trabalho próprios de Sociologia do Esporte ou então naqueles grupos que prevêem um espaço e abertura para discussão do esporte em uma perspectiva sociológica, histórica e política. Fator decisivo e motivador para escrita desse texto foi também termos nos deparado com o último número da revista Motrivivência (n. 32-33) que ao apresentar um dossiê sobre os megaeventos esportivos, contribui decisivamente para lançar essa discussão sobre "legados" esportivos de forma sistemática no campo acadêmico-científico da Educação Física no Brasil, reeditando, inclusive, a própria iniciativa já ensaiada no mesmo periódico no ano de 2006.

Dito isso, convém avançarmos ao argumento central que orienta todo o esforço crítico-reflexivo que mobilizamos no decorrer do texto e que tem como ponto de partida o seguinte questionamento: Quais dimensões sociais que o contexto de realização dos megaeventos trouxe ou, por ventura, pode trazer para o Brasil? Primeiramente, devemos deixar claro que por megaeventos esportivos entendemos a conjuntura material e simbólica, o que inclui a mobilização de muitos agentes e estruturas dos mais distintos campos sociais (esportivo, econômico, político, midiático etc.), constituída em torno do esporte fazendo do mesmo tanto um meio quanto um fim para reunir adeptos e consumidores em escala global e de modo a romper com as fronteiras culturais e econômicas que se impõe em termos de nação, região e grupos, ou no mínimo, imprimir novos sentidos e dinamismos as mesmas.

Por sua vez, exemplos desses megaeventos esportivos são os Jogos Pan-americanos, os Jogos Olímpicos e as Copas do Mundo de Futebol, sendo que o primeiro já foi realizado no Brasil em 1963 e, recentemente, em 2007, assim como a Copa do Mundo que o Brasil já sediou em 1950 e repetirá o feito em 2014. Já os Jogos Olímpicos, o Brasil e, diga-se de passagem, nenhum outro país da América do Sul teve antes a oportunidade de sediar e, talvez, seja por isso que a edição dos Jogos Olímpicos e Paraolímpicos a ser realizado na cidade do Rio de Janeiro/ Brasil em 2016 esteja se revestindo de tantas expectativas, anseios e discursos que ora assumem contornos carregados de tons emocionais e apelativos, ora de tons políticos, salvacionistas e, 
acima de tudo, centrados na idéia do esporte como apaziguador e atenuador das tensões.

Visto por um ângulo global e conjuntural, os megaeventos esportivos nessas últimas décadas, no nosso ponto de vista, elucidam com bastante clareza o movimento de expansão e consolidação do mercado esportivo capitalista. Se pensarmos, sobretudo, nesses últimos anos isso é bastante verdade, na medida em que o continente africano foi "premiado" para sediar sua primeira Copa do Mundo, a qual veio a ser realizada nesse ano de 2010 na África do Sul, além, é claro, dos recentes exemplos constituídos na figura da Copa do Mundo que depois de sessenta anos retorna ao Brasil e dos Jogos Olímpicos que pela primeira vez será sediado por um país sul-americano, curiosamente, o próprio Brasil. E o que dizermos dos Jogos Olímpicos de Pequim realizados na China em 2008? Nesse propósito cabe aqui apenas uma observação: muita gente trabalhando e consumindo. Por conseguinte, essas escolhas realizadas pela FIFA e pelo COI (incluamse também as grandes corporações) talvez tenham alguma relação com o fato da Europa estar enfrentando nessa última década uma crise política e, principalmente, econômica que reflete diretamente em seus mercados de modo que os mesmos se tornaram frágeis e saturados do ponto de vista da demanda e da solicitação em massa de seus serviços por parte dos consumidores.

Não obstante essa lógica mercantil e consumista sugerida é de suma importância notar que o processo de expansão e consolidação do mercado esportivo não opera apenas por via da desterritorialização do espaço e mundialização da economia e da cultura. Existe também no interior desse jogo a constante preocupação de "superar" - não no sentido de resolver - as barreiras de classe, de idade, de gênero, de preconceitos com deficientes, com homossexuais etc. No esporte isso se traduz muito bem no desejo dos organismos responsáveis pela gestão esportiva assim como dos grupos econômicos e políticos adjacentes a esses organismos em disseminar o raio de ação de suas práticas (nesse caso, as esportivas) para vários segmentos populacionais, condição essa que, na linguagem da aristocracia esportiva, tem seu equivalente em espalhar o fair-play pelo mundo como eles insistem em crer.

Nesse quesito mencionado, a primeira iniciativa que nos veio à mente talvez seja a criação das "Olimpíadas dos Portadores de Deficiência" no ano de 1960 em Roma, as quais vieram a ser oficializadas pelo COI em 1984 na 
condição de Jogos Paraolímpicos. Como exemplo mais recente temos a efetivação do $1^{\circ}$ Jogos Olímpicos da Juventude realizado em Cingapura entre os dias 14 e 26 de agosto de 2010. Vale notarmos que no último caso, muito possivelmente o que deve estar em jogo nessa iniciativa, dentre outros fatores, é o fato dos jovens nessas últimas décadas estarem se tornando a população ativamente mais consumidora dos produtos esportivos e da indústria do entretenimento no mundo.

Se no âmbito do esporte regulamentado e gerenciado pelo COI, esses exemplos são bastante elucidativos e caricaturais, no âmbito do esporte amador e não regido pelo COI, poderíamos citar os Jogos Olímpicos Gays que foram para sua oitava edição agora em 2010 quando da ocasião da realização do evento em Colônia/Alemanha no mês de agosto. Interessante notarmos que iniciativas de participação no esporte federado e regido por instâncias legitimadoras, independentemente do público referido ou da causa defendida, parecem soar como uma conquista e, de fato, o é, mas não no sentido que uma leitura preliminar tende a conferir, ou seja, exaltando as diferenças e procurando invertê-las. Trata-se sim de uma conquista: uma conquista ao direito de consumir e buscar uma distinção no universo esportivo quando senão um subterfúgio na busca de consagração e legitimação mediante as redes sociais mais amplas.

Em que se pesem essas breves incursões e argumentações desenvolvidas, podemos dizer, portanto, que o nosso principal "legado" (usamos o termo embora não concordemos com a forma com que o mesmo vem sendo tratado pela academia, isto é, como um a priori - por vezes, carente de uma reflexão sócio-filosófica mais profunda - para subsidiar algumas primeiras análises e avaliações sobre a temática dos megaeventos) é a entrada "oficial" do Brasil no circuito dos megaeventos esportivos, eles próprios inseridos em um sistema mercadológico de práticas e consumos regidos por leis de oferta e procura da sociedade capitalista. Dito em outros termos, somos tendentes a crer que o grande "legado" dos Jogos Pan-americanos Rio-2007, por exemplo, tenha sido a contribuição para expansão de um mercado esportivo que certamente não está preocupado com a formação de praticantes esportivos, mas com a formação de disposições práticas para o consumo do esporte e dos produtos esportivos adjacentes.

Quanto aos "legados" (ou promessas de "legados") da Copa do Mundo de Futebol de 2014 e dos Jogos Olímpicos de 2016 entendemos como um tanto quanto 
prematuro falar nesses termos. Esse tipo de discurso, aliás, é bastante compreensível em se tratando dos órgãos e grupos políticos que estiveram à frente das campanhas de candidatura apresentadas a FIFA e ao COI, assim como no caso dos mais distintos especialistas culturais que concorrem no interior do campo midiático. Interessante também notarmos que o "discurso dos legados" já passa a fazer parte, com certa freqüência, do dia-a-dia dos mais diferentes agentes que se movimentam no espaço social brasileiro, constituindo e reforçando, de certo modo, aquele fenômeno social que o filósofo italiano Umberto Eco (1984) veio chamar de "falação esportiva" e que, no caso da análise da relação entre o universo de produção midiática e o universo esportivo no Brasil, veio a ser recuperado como conceito analítico e estruturante pelo Professor Mauro Betti (2009) para pensar o "esporte telespetáculo".

Essa "falação" sobre os "legados", por sua vez, reforça ainda uma espécie de inversão de prioridades no que se refere à estrutura de planejamento para sediar os megaeventos. Referimo-nos ao fato de que ao invés de nos preocuparmos primeiramente em organizar esses eventos da melhor e mais honesta forma possível - afinal o que está em movimento, por mais questio- nável que seja, é a veiculação de uma suposta identidade brasileira - estamos voltando nosso foco quase que exclusivamente para a dimensão dos "legados" e, sobretudo, do "legado esportivo-social". Essa preocupação com o "legado social" dos megaeventos, de fato, é comovente, ainda mais se pensarmos no fato de que em nosso país mais de um terço da população vive em condições subumanas e de miséria. No entanto, o que "não conseguimos entender" é por que esse discurso sobre o "legado social" do esporte só veio vir à tona de uma maneira mais incisiva e midiatizada justamente no momento em que o Brasil se prepara para sediar uma Copa do Mundo e uma edição dos Jogos Olímpicos?

Gostaríamos de saber também se o acréscimo do termo "legado social", num primeiro momento, nos projetos de candidatura brasileira como país-sede dos megaeventos e, num segundo momento, nos projetos e subprojetos de financiamento dos referidos eventos esportivos que estão sendo apresentadas nas instâncias públicas ou então privadas, garante alguma vantagem simbólica e, especialmente, material aos agentes, estruturas e instituições proponentes dos mesmos? Muito possivelmente sim. Entretanto, o mais lamentável nessa lógica não é o uso da logomarca "legado social" 
(responsabilidade social também é um jargão freqüentemente utilizado) para justificar, angariar fundos e promover os megaeventos, mas o uso inadequado do que é arrecadado ou "financiado".

Diante dessa incoerência, resta a nós, inseridos nos âmbitos acadêmicos - desde que armados de um senso crítico e de reflexividade - procurarmos desfazer ou, no mínimo, alertar sobre os perigos de levarmos a diante essa crença do "legado esportivo-social". Apenas para apontar um dos contratempos de promoção social ou acadêmica dessa crença poderíamos exemplificar com o fato de que ao evocála e reproduzi-la irrefletidamente corremos o sério risco de construirmos nos próximos anos de forma automática, consensual, tornada habitus e, portanto, encarnada nos corpos, uma cultura do "legado social", sem, no entanto, superar ou no mínimo amenizar os graves problemas de desigualdade que a sociedade brasileira carrega como traço singular do tipo de modernidade que aqui foi construída no decorrer da história. Acrescendo mais elementos a essa análise e usando a expressão do Professor Jay Coakley (2010), correríamos também o sério risco de nos tornarmos os novos "evangelizadores" do esporte.

Não obstante esse conjunto de amarrações teóricas é imprescin- dível frisarmos que nosso argumento não se constitui no sentido de colocar sob suspeição o caráter educativo ou, até mesmo, de transformação social que a prática esportiva, desde que devidamente desenvolvida, pode fomentar no interior da sociedade brasileira. Para isso, entretanto, existem muitas pessoas esforçadas, dotadas de muito mais boa vontade ainda e, na maioria das vezes, ganhando salários e bolsas-auxílios irrisórias para desenvolver o trabaIho com o esporte na perspectiva do "corpo-a-corpo" e sem o menor reconhecimento. Além disso, o espaço das aulas de Educação Física nos colégios e nas escolas, somadas a uma proposta de "educação olímpica", também se constitui como um espaço fértil, senão para algumas primeiras mudanças possíveis e de urgência, ao menos para a conscientização social de alguns indivíduos como bem sugeriu a Professora Kátia Rubio (2009).

Dito de outro modo, nosso argumento quanto aos "legados sociais" do esporte em se tratando dos megaeventos é que não devemos depositar nossas esperanças de construção de um projeto de sociedade mais justa e igualitária na realização pontual de uma Copa do Mundo ou de uma edição dos Jogos Olímpicos. Além disso, devemos ser reflexivos o bastante para não acabarmos reeditando sob 
termos re-estilizados, quando senão sob outra roupagem, o discurso salvacionista do esporte, o qual, diga-se de passagem, é teoricamente interessante para os grupos dominantes e, em contrapartida, com efeitos práticos quase que nulos e inatingíveis para os grupos dominados.

Ainda sobre os "legados esportivo-sociais" poderíamos demonstrar a ambigüidade desse projeto evocando uma variedade de exemplos referentes ao período pósJogos Pan-Americanos Rio-2007, que veio e ainda está a contradizer a fase propositiva de realização desse megaevento. Para não nos estendermos muito, basta mencionar apenas a construção dos grandes complexos esportivos nas regiões mais nobres do Rio de Janeiro e, portanto, vetadas geograficamente aos estratos sociais mais baixos. Some-se a essa análise o imperativo de que a segurança pública de Estado impõe um poder restritivo à circulação em larga escala, nos bairros reservados às elites, de indivíduos que habitam nos morros e que, por conseguinte, carregam as marcas desses espaços de maneira visível em seus próprios corpos.

Ocorre também dos habitantes dos morros, interiorizarem em suas formas de ver o mundo, as divisões físicas e materiais do espaço social conforme lhes são apre- sentadas pelas classes dominantes. A isso, o sociólogo francês Pierre Bourdieu (1989; 2007) deu o nome de violência simbólica: violência sutil, dissimulada, que conta com a cumplicidade tácita dos dominados e que exerce um grau de efeito dominante proporcional ao desconhecimento que engendra. Essas amarrações teóricas, por sua vez, nos sugerem a hipótese de que muito provavelmente o monopólio da violência física na figura do Estado está relacionado, no caso do Brasil, ao exercício da violência simbólica sobre as classes mais baixas.

Nessa mesma linha de raciocínio, é possível ainda indagar se a mera construção de espaços esportivos que possibilitassem a oferta de esportes historicamente pouco acessíveis aos estratos sociais mais baixos garantiria a "inclusão" dos indivíduos pertencentes a essas mesmas classes no universo esportivo de modo que pudessem se apropriar de uma forma mais justa da distribuição dos capitais em jogo? Do mesmo modo e como bem foi demonstrado por Bourdieu e Darbel (2003) no clássico estudo que realizaram sobre os museus na Europa, para tornar a arte mais "acessível" seria apenas necessário construirmos mais museus? Óbvio que não. Pelo contrário, possibilitar o acesso coletivo à arte, aos esportes "culturalmente restritos" e o que 
quer que seja não se trata apenas de uma questão de maximizar os locus de oferta ou ainda construir esses espaços em lugares estratégicos onde as classes mais pobres e excluídas da cultura legítima pudessem ter acesso - sem o peso do veto simbólico e físico anteriormente comentado - a esse conjunto de bens e práticas culturais.

Dito em outros termos, para se construir uma cultura de acesso à cultura erudita é necessário, antes de tudo e principalmente, desenvolver nos agentes um senso de julgamento e apreciação estética para que efetivamente possam desfrutar e consumir, por exemplo, os códigos artísticos e esportivos inerentes a determinadas práticas circunscritas. Esse senso de julgamento e apreciação, por sua vez, só se constrói mediante o trabalho e retorno reflexivo dos agentes sobre eles mesmos e, nesse quesito, a instituição escolar tem, ou ao menos deveria ter, um papel fundamental e, sobretudo, engajado. Tal retomada, entretanto, não é isenta de confrontações, uma vez, que quando as classes populares se apropriam das práticas eruditas e distintas da cultura legítima, as classes mais altas logo tratam de procurar um lucro distintivo em outras práticas de modo a reavaliar e ressignificar a cultura legítima.

Diante, portanto, desse quadro social rapidamente esboçado podemos formular outra questão que os próprios argumentos apresentados nos parágrafos acima já dariam conta de responder: De que forma as crianças e adolescentes que se amontoam nos morros cariocas poderiam desenvolver um habitus para a prática esportiva utilizando e se usufruindo do Complexo Aquático Maria Lenk situado no bairro Barra da Tijuca no Rio de Janeiro? Parece irônico, mas é exatamente esse tipo de questionamento que deveriam ser ponderados pelos porta-vozes políticos do "legado social" dos megaeventos antes de saírem espalhando para a sociedade brasileira pelas vias insidiosas do campo midiático a idéia de que a realização de uma Copa do Mundo ou dos Jogos Olímpicos pode contribuir diretamente para reduzir as desigualdades no país. O esporte, de fato, e conforme foi dito anteriormente, tem seu papel mobilizador nesse sentido recobrado desde que associado a uma política de re-educação que não necessariamente está vinculada somente ao esporte escolar, mas ao esporte de uma forma geral e em seu caráter polissêmico de patrimônio cultural da humanidade.

Por conseguinte, essas confusões a respeito das inter-relações entre megaeventos, "legado", esporte e redução das desigualdades sociais, em parte, se devem à falta de reflexão metódica e sistemática 
por parte de quem está à frente da execução, divulgação e, até mesmo, da abordagem acadêmico-científica dessas temáticas. E mais, diríamos que essas confusões não se restringem apenas aos supostos "legados sociais", mas também avançam para a esfera dos chamados "legados econômicos" e "desenvolvimentistas". Há, nesse propósito, todo um movimento social articulado em torno da crença de que o progresso econômico brasileiro (segundo se dissemina nas mais diferentes instâncias midiáticas, o Brasil possivelmente será a quinta economia do mundo em 2016) será elevado a novos patamares por conta dos megaeventos.

De fato, podem ocorrer uma série de alterações sociais no âmbito da circulação turística e desenvolvimento do potencial turístico de algumas cidades e regiões brasileiras, assim como um acréscimo na exportação dos produtos e bens de consumo produzidos no Brasil para o exterior. Entretanto, entendemos que, do ponto de vista econômico, o impacto direto e, até mesmo, indireto da realização dos megaeventos no Brasil são questionáveis e os especialistas em macroeconomia podem nos corroborar e são os mais indicados para tecerem esse tipo de análise.

Devemos também frisar que essa crença no "legado econô- mico" está intimamente associada ao discurso do "legado social" tanto na esfera do senso comum quanto na esfera política e científica (nesta última talvez por conta de uma indevida utilização ou apropriação de alguns referenciais teóricos das Ciências Sociais e Econômicas), uma vez que quase que milagrosamente se espera que do progresso e crescimento econômico possam ser resolvidos os dilemas sociais brasileiros, argumento esse, que cai por terra ao notarmos que dos anos 1940 até os anos 1980, conforme indica o sociólogo brasileiro Jessé Souza (2006), a economia do Brasil foi a que mais cresceu no mundo sem, no entanto, reduzir os índices de desigualdade e injustiça social.

Se no campo da economia e no âmbito da redução das desigualdades é no mínimo duvidoso e controverso falar de "legado" dos megaeventos, no universo da cultura onde constantemente são ativados elementos e esquemas próprios de uma economia simbólica e emocional geneticamente interligada à oferta e consumo esportivo, podemos sim pensar numa espécie de "legado" dos megaeventos esportivos para o Brasil e para os brasileiros. Sem a pretensão de aprofundar nessa temática que certamente daria alguns pares de artigos, cabe-nos primeiramente dizer 
que no âmago de nossa história enquanto nação autônoma foi construída uma identidade nacional que faz às vezes de uma "fantasia compensatória" de que apesar de termos todos os nossos problemas sociais, nenhum povo nesse planeta é tão "hospitaleiro", "simpático", "sensual", com festas tão bonitas e que jogue um futebol "gingado" e "moleque" como nós jogamos. Indiscutivelmente, a construção efetiva e duradoura desse mito se deve em muito às idéias de Gilberto Freyre (1996; 2000), Sérgio Buarque de Holanda (1994) e, nessas últimas décadas, de Roberto DaMatta (1979). As reflexões desses autores engendram uma análise de quem gosta do Brasil e, portanto, essas idéias acabam fazendo a cabeça do "BRASIL MODERNO".

Por conseguinte, esses elementos identitários, emocionais e efusivos supracitados são bastante recorrentes no cotidiano brasileiro e, dentre outras oportunidades, transpareceram explicitamente na entrevista do Presidente da República Luiz Inácio Lula da Silva concedida aos jornalistas estrangeiros e nacionais no dia 02 de outubro de 2009 em Copenhague/Suíça após o anúncio da cidade do Rio de Janeiro como sede dos Jogos Olímpicos de 2016. Mas talvez o que mais de impressionante o Presidente Lula (2009) tenha dito nessa oportunidade foi que por conta da escolha do Rio de Janeiro como sede dos Jogos Olímpicos de 2016, o Brasil ganhou definitivamente sua cidadania internacional. Cabe para este fato apenas uma nota de que se o escritor e dramaturgo Nelson Rodrigues tivesse visto a referida cena ou ouvido sobre a mesma, mais uma vez teria escrito sobre a "síndrome de vira-latas".

O que, entretanto, queremos sugerir com essa passagem é que a conjuntura e a escolha do Brasil como sede dos principais megaeventos esportivos do planeta já está contribuindo para reacender alguns elementos identitários que vêm sendo articulados de forma singular à cultura esportiva brasileira mediante a implantação de um mercado esportivo no decorrer de nossa história. Além disso, ainda que entendamos que, de fato, a singularidade do projeto de construção da modernidade brasileira não reside e não se assenta sobre as características identitárias e emocionais do "homem-cordial que, associada como resposta compensatória e imediata as nossas mazelas e misérias numa mistura de traços tradicionais, pré-modernos e modernos, constitui o chamado "dilema nacional" identificado na abordagem teórica de DaMatta (1979), não podemos negar que a conjuntura dos megaeventos, na qual adentramos nesses últimos 
anos e no mínimo pela década que está por vir, de alguma forma está mexendo com o auto-estima e o brio de uma boa parte da população brasileira.

No entanto, afirmações ou elucubrações mais precisas sobre esse argumento requerem um trabalho empírico minucioso, exaustivo e guiado teoricamente. $\mathrm{O}$ que podemos sugerir ou, até mesmo, afirmar no presente momento, é que a perspectiva de identificação de um provável "legado simbólico" e "emocional" dos megaeventos esportivos tem potencialidade de se constituir como um programa de pesquisa que ao lado da constatação de que um dos principais "legados" dos megaeventos, de fato, é a expansão de um mercado esportivo preocupado com a formação de disposições para o consumo, daria conta de englobar aquilo que poderíamos denominar de uma "sociologia dos 'legados' dos megaeventos esportivos".

Como última observação, devemos frisar que para que uma "sociologia dos 'legados' dos megaeventos esportivos" possa se constituir de forma rigorosa e reflexiva, é necessário que deixemos primeiramente de tomar a noção de "legado" (legatum) como um ponto de partida de nossas análises e, passemos, a tratá-la na condição de uma categoria sociológica de reflexão sócio-filosófica e de acesso e interpretação da realidade empírica. Esse deslocamento reivindicado, por conseguinte, é de extrema urgência para subsidiar os estudos no âmbito da Sociologia do Esporte e das Políticas Públicas de Esporte e Lazer, uma vez que ao tomarmos a idéia de "legado" de forma naturalizada ou então como um à priori, muito possivelmente nos predispomos em anular ou, até mesmo, desfazer o caráter processual das relações sobre as quais nos debruçamos. Certos ainda de que não foi possível aprofundar todas as frentes de apreciação aqui abertas, reservamos uma discussão com maior grau de acuidade teórica e embasamento empírico para oportunidades futuras.

\section{Referências}

BETTI, M. A janela de vidro: esporte, televisão e educação física. Campinas: Papirus, 1998.

BOURDIEU, P. O poder simbólico. Lisboa: Difel, 1989.

BOURDIEU, P. A dominação masculina. Rio de Janeiro: Bertrand Brasil, 2007.

BOURDIEU, P; DARBEL, A. O amor pela arte: os museus de arte na Europa e seu público. São Paulo: Zouk, 2003.

COAKLEY, J. Deporte y identidade nacional: El caso de América 
Latina. Palestra de abertura do $2^{\circ}$ Encontro da Asociación Latinoamericana de Estudios Socioculturales Del Deporte, Maracay, Venezuela, set. 2010.

DAMATTA, R. Carnavais, malandros e heróis: para uma sociologia do dilema brasileiro. Rio de Janeiro: Zahar, 1979.

$\mathrm{ECO}, \mathrm{U}$. Viagem na irrealidade cotidiana. Rio de Janeiro: Nova Fronteira, 1984.

FREYRE, G. Sobrados e mucambos: introdução à história da sociedade patriarcal no Brasil. Rio de Janeiro: Record, 1996.

FREYRE, G. Casa Grande \& Senzala: introdução à história da sociedade patriarcal no Brasil. Rio de Janeiro: Record, 2000.

HOLANDA, S. B. Raízes do Brasil. Rio de Janeiro: José Olympio, 1994.
RUBIO, K. Esporte, educação e valores olímpicos. São Paulo: Casa do Psicólogo, 2009.

SILVA, L. I. L. Entrevista aos jornalistas após a escolha do Rio de Janeiro como sede dos Jogos Olímpicos de 2016, 02 de outubro de 2009. Disponível em: < http://www.itamaraty. gov.br/sala-de-imprensa/ discursos-artigos-entrevistas-eoutras comunicacoes/prsidentedarepublica-fede rativa-dobrasil/entrevista-coletivaconcedida-a-jornalistas $>$ Acesso. 18 out. 2010.

SOUZA, J. A invisibilidade da desigualdade brasileira. Belo Horizonte: UFMG, 2006.

Recebido: outubro/2010 Aprovado: novembro/2010 